\title{
A PRODUÇÃO DA NATUREZA NA VILA DO JACARÉ - MANACAPURÜ/AM - BRASIL: MODO DE VIDA, TERRITÓRIO E CAMPESINATO
}

\author{
Jonathas Laborda Neves \\ Mestrando do Programa de Pós-graduação em Geografia - UFAM \\ Universidade Federal do Amazonas \\ ionathas.j|@hotmail.com \\ Manuel de Jesus Masulo da Cruz \\ Professor Doutor do Programa de Pós-graduação em Geografia - UFAM \\ Universidade Federal do Amazonas \\ masulo@bol.com.br
}

\begin{abstract}
RESUMO: Trata-se de um estudo que busca compreender, a partir da Vila do Jacaré (ManacapuruAM), a produção da natureza no território, atentando-se ao campesinato e ao modo de vida dos moradores. Propõe analisar o processo de crescimento da comunidade e o perfil de moradores da Vila do Jacaré tendo em vista principalmente as obras de infraestrutura ao longo do tempo e pontuar a relação da vila com o lago do Jacaré. Para tal, o presente artigo parte da análise das relações campesinas e da apropriação da natureza ambas desenvolvidos por esses camponeses - ribeirinhos em seu ir e vir - bem como o impacto que as transformações no uso da terra e da pesca e as coercitividades por órgãos governamentais trouxeram a essa relação pelos seus modos de vida. Por isso cabe, no trabalho, um levantamento socioambiental de onde se deseja perceber e compreender a produção do território a partir dos aspectos socioculturais dos comunitários.
\end{abstract}

Palavras-chave: produção da natureza; território; campesinato

\section{INTRODUÇÃO}

O termo camponês ainda é algo temido se não pouco compreendido no Brasil, muitos países latino-americanos até reconhecem a existência do camponês enquanto classe histórica, enquanto o Brasil se abstém de nomear esse agricultor familiar de camponês os outros estão se não investindo no mesmo para ajudar a reprodução do capitalismo enquanto sistema estão se valendo da produção camponesa para angariar lucro, o que por si só já configura (re) produção do capital.

No estigma da apropriação elencaremos uma categoria de análise da Geografia: o território, que é aquele espaço apropriado. Nesse sentido, a apropriação da natureza caminha de mãos dadas com a configuração do território que, por conseguinte elenca a premissa do poder/posse sobre a terra, entendido aqui como o campo ("a roça"). A abordagem sobre território, campesinato e a produção da natureza nesse cerne propõe uma reflexão que deve ser pautada na inserção de seus atores enquanto produtores diretos desse território, afim de que se compreenda a realidade e as singulares relações desenvolvidas sobre seu território para que este não seja percebido unicamente como aglomerado natural e como espaço de interação entre homem-natureza, em especial o espaço de vida da comunidade de Nossa Senhora 
A PRODUÇÃO DA NATUREZA NA VILA DO JACARÉ - MANACAPURU/AM - BRASIL: MODO DE VIDA, TERRITÓRIO E CAMPESINATO

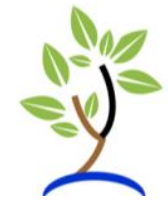

do Carmo ${ }^{1}$, uma vez que são estas relações que fundamentam sua organização territorial e social. Portanto partiremos de uma análise do campesinato na Amazônia como parte integrante do modo capitalista de produção, portanto o camponês entendido aqui como classe é o agente direto de apropriação sobre a terra como já supracitado.

Prezar-se-á, por fim, refletir sobre questões ligadas à formação do território pela comunidade a partir do cotidiano, objetivando aprofundar cada vez mais as discussões sobre o território e territorialidade em seus diversos arranjos e relações. Usaremos neste intuito o aporte das discussões elencadas por estudiosos como Ariovaldo Umbelino de Oliveira, Theodor Shanin, Karl Marx, Alexander V. Chayanov e Neil Smith.

\section{MATERIAIS E MÉTODOS}

O presente trabalho se insere, portanto no campo exploratório (ANDRADE, 1999), de cunho qualitativo, mas também quantitativo. É o estudo de um lugar, lugar este em que as relações entre o rural e urbano são híbridas, elas coexistem no mesmo sob o mesmo território sem, no entanto, se misturarem, fortalecendo essa relação dialética de estarem imbricados, mas se colocarem como díspares.

Usaremos a triangulação entre as metodologias e assim acreditamos andar de acordo com o que defende Goldenberg (2003) dizendo que a combinação de metodologias atribui ao objeto estudado significado ainda mais coeso.

A coleta de dados primários extraídos de formulários e de entrevistas abertas e fechadas com os moradores, e os dados vindos de órgãos governamentais, os dados secundários virão de fontes como IBGE e INCRA

\section{REVISÃO DE LITERATURA}

Camponês de acordo com Moura (1986) é aquele que mais se envolve diretamente com os segredos da natureza, esse indivíduo vive da terra e do que ela produz, plantando e colhendo o alimento que atende a todas as classes do rico ao pobre. Já em Shanin (1980) temos classificados características básicas para a descoberta do indivíduo camponês: 1) a propriedade rural/familiar é a unidade básica para organização social e econômica; 2) trabalho familiar; 3) a agricultura é a principal atividade e significa fonte de renda.

\footnotetext{
${ }^{1}$ Comunidade Nossa Senhora do Carmo foi o nome que outrora recebeu a Vila do Jacaré, que popularmente era também chamada de Boca do Jacaré e segundo Vasconcelos (2017) foi elevada à categoria de comunidade em 23 de fevereiro de 1976, posteriormente elevada à categoria de Vila em 1988, feito isto chamaremos a partir de então a comunidade somente de vila que foi o de sua ultima elevação.
} 
A PRODUÇÃO DA NATUREZA NA VILA DO JACARÉ - MANACAPURU/AM - BRASIL: MODO DE VIDA, TERRITÓRIO E CAMPESINATO

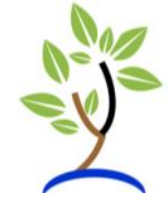

Enquanto para Oliveira (2006) entende o conceito camponês politicamente, por isso é uma classe como classe

\begin{abstract}
sui generis do capitalismo, sua singularidade se manifesta na experiência única de reprodução, a qual se baseia no próprio controle sobre o trabalho e sobre os meios de produção. É o que Ihes permite conservar a capacidade de produzirem seus próprios meios de vida, ainda que as condições concretas de reprodução de cada família nem sempre o determine. (OLIVEIRA, 2006, p.16).
\end{abstract}

$\mathrm{Na}$ Amazônia o camponês tem uma particularidade a mais, o rio que é percebido como um "ente" garantidor, assim como a terra, de seu sustento. Por isso, a adoção do termo adaptado de Witkoski (2010) por Cruz (2007) camponês-ribeirinho será captado no desejo de bem definir esse indivíduo multifacetado que tem o controle direto sobre a terra que habita e produz, este indivíduo que vive da agricultura, da pecuária, suinocultura do extrativismo vegetal mais vive sobre a Amazônia tendo o rio comandando a vida.

O território, outra palavra-chave usada neste consiste em todo espaço definido e delimitado por e a partir das relações de poder, podendo ser propínquo ou segmentado, variando de uma gleba de terra "dominada" pela Igreja, ou ainda por um núcleo familiar e/ou até mesmo um bloco político ou econômico constituído por países membros.

Sendo assim, toda produção é apropriação da natureza pelo indivíduo no interior e medida por uma determinada forma de sociedade. Tão logo, o território é também produto do espaço, onde a ocupação dele é consequentemente resultado da apropriação conduzida por um indivíduo, que é o agente diretamente envolvido em sua concepção.

Posto isso, no que tange a segunda abordagem no presente trabalho, temos o Térritório que por sua vez, conceitualmente deve ser compreendido, conforme alude Oliveira (2002)

\begin{abstract}
Como síntese contraditória, como totalidade concreta do processo/modo de produção/distribuição/circulação/consumo e suas articulações e mediações superestruturais (políticas, ideológicas, simbólicas etc) em que o estado desempenha a função de regulação. O território é assim produto concreto da luta de classes travada pela sociedade no processo de produção de sua existência (OLIVEIRA 2002, p.74).
\end{abstract}

O Território é fruto a relação entre os agentes sociais, políticos, econômicos e estatais interferindo na gestão do espaço geográfico, pelo poder, seja uma dominação física material, a terra por exemplo, ou pela intersubjetividade no que concerne a cultura, por exemplo os símbolos. 
A PRODUÇÃO DA NATUREZA NA VILA DO JACARÉ - MANACAPURU/AM - BRASIL: MODO DE VIDA, TERRITÓRIO E CAMPESINATO

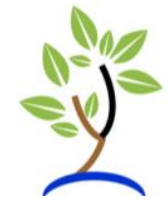

Em Smith, a noção de "produção da natureza" e a sua "corporificação" revela a sede incessante da acumulação, cuja leitura de mundo repousa sobre a perspectiva de uma natureza como "recurso" não finito, sob o capricho da reprodução ampliada do capital. Onde, na medida em que essa perspectiva ganha cada vez mais fôlego, podemos problematizar o papel da tecnologia e dos avanços no campo científico, ou seja, a "ciência" vista como uma possibilidade de intervenção "externa" para o aperfeiçoamento e modificação da natureza, de modo a subjugá-la ao ritmo da produção capitalista.

Smith refuta o embate segundo ele paradoxal, em se pensar na idéia de produção da natureza, haja visto que a natureza geralmente é posta como algo dado, portanto, inconcebível de produzir. Entretanto, a transformação do tido como natural apresentase consubstancialmente materializada pela vida diária, logo é produto social. Logo, a produção da natureza é também a produção do espaço, do território, do lugar.

\section{RESULTADOS E DISCUSSÃO}

Os resultados preliminares percebidos, aferidos e interpretados mostram que a produção da natureza na Vila do Jacaré antes da ida do Estado, ou por assim dizer, "do capital ao trabalho" se deu pela necessidade, uns de moradia e a massa estava se apropriando das terras de um senhor naquele lugar, apoiados nisso foram para tomar posse também. Outros, impulsionados pela gama diversa de atividade próximas a trazer renda a família, a saber: a pesca no lago do Jacaré e a agricultura em terra firme.

Outros ainda, pela segurança que não tinham em outras vilas com um quantitativo maior de drogas, usuários e violência. Hoje, com os investimentos em abertura de nivelamento de ruas, área de recreação comunitária, escola e UBS (Unidade Básica de Saúde) a Vila tem sido procurada e esses esse crescimento a presente pesquisa pretende levantar.

\section{REFERÊNCIAS}

ANDRADE, M. M. Introdução à metodologia do trabalho científico: elaboração de trabalhos na graduação. 4º ed. São Paulo: Atlas, 1999.

CRUZ, M. J. M. Territorialização camponesa na várzea da Amazônia. 2007 (Doutorado em Geografia Humana) - Faculdade de Filosofia, Letras, e Ciências Humanas, Universidade de São Paulo: São Paulo, 2007. Doi:10.11606/T.8.2007. tde03122007-112229. Acesso em: 24 jul. de 2017.

GOLDENBERG, M. A Arte de Pesquisar: como fazer pesquisa qualitativa em ciências sociais. 8aㅡ ed. Rio de Janeiro: Record, 2004. 110 p. 
MOURA, M. M. Camponeses. Série Princípios. São Paulo: Ática, 1986.

OLIVEIRA, A. U. A Geografia Agrária e as transformações territoriais recentes no campo brasileiro. In: CARLOS, A. F. A. (Org.). Novos caminhos da Geografia. São Paulo: Contexto, 2002.

OLIVEIRA, A. U.. Prefácio. In: PAULINO, E. T. Por uma Geografia dos camponeses. São Paulo: Editora UNESP, 2006.

SHANIN, T. A definição de camponês: conceituações e desconceituações: o velho e novo em uma discussão marxista. IN: Estudos CEBRAP, n. 26, Editora Vozes, 1980.

SMITH, N. Desenvolvimento Desigual: Naureza, capital e a produção do espaço. Rio de Janeiro: Bertrand Brasil, 1988.250p.

VASCONCELOS, B. T. Entrevista I. [jul.2017]. Entrevistador: Jonathas Laborda Neves. Manacapuru, 2017. 1 arquivo .mp3 (47:57min.). Arquivo pessoal. A deste artigo.

WITKOSKI, A.C. Terras, florestas e águas de trabalho: os camponeses amazônicos e as formas de uso de seus recursos naturais. 2ª edição. São Paulo: Annablume, 2010.

Recebido em 13/03/2018

Aceito em 30/05/2018 